\title{
ESPERANZA-FUGACIDAD-FRAGILIDAD. PROPUESTAS PARA UN MOTIVO DE LA POESÍA DE GARCILASO
}

Uno de los aportes más significativos que ha conocido en los últimos años el análisis textual es la consideración de los aspectos narrativos del discurso poético. Si esta dimensión se echaba de menos en el estudio de gran cantidad de textos, era una grave omisión en los de poetas como Garcilaso que otorgan singular importancia a los contenidos. En este caso hay una razón histórico-cultural que así expone P. Kristeller:

"El humanismo reúne en sus aspiraciones y en sus logros la destreza literaria, la erudición histórica y filológica y la sabiduría moral: tres facetas que para nosotros son claramente distintas pero que para los humanistas eran inseparables" 1.

Ahora bien, como dice Greimas, al referirse a dicho paso fundamental, el resultado ha sido el planteo de nuevos problemas, entre los cuales no es el menor el del análisis de las isotopías ${ }^{2}$. En esta dirección se orientan las indagaciones de nuestro trabajo. $\mathrm{Y}$ hay aún algo más. El estudio de los textos poéticos se ha ejercitado, sobre todo, dentro de los límites de una sola composición. También ha habido cambios últimamente en este sentido y con re-

1 Kristeller, P. O., "El territorio del humanista", Historia y critica de la literatura española, al cuidado de F. Rico, Barcelona, 1980, vol. II, pág. 34.

2 Greimas, A. J., "Hacia una teoría del discurso poético", Ensayos de semiótica poética, Barcelona, 1976, pág. 25. 
sultados importantes, pero aún quedan muchos caminos para recorrer. Nuestra intención es, pues, la de analizar ciertos contenidos presentes en la obra de Garcilaso, considerándola como un texto total ; aunque tomando en cuenta, por supuesto, las diferencias primordiales que separan a unas composiciones de otras.

Nuestro poeta fue amigo de utilizar expresiones que repetía en varios poemas, en términos muy similares y con un sentido análogo. Ya Herrera señaló tal tipo de aproximaciones entre el Son. X, el XXVI y la Égl. II ${ }^{3}$. Más tarde, Keniston también las subrayaría entre el Son. X, el XXVI y la Can. III 4 . Como se puede apreciar, ambos coinciden en dos casos y mencionan otra más, diferente. En total, se trata de estos cuatro:

Pues en una ora junto me llevastes todo el bien que por términos me distes,

Son. X, 9-10.

¡O quánto bien s'acaba en solo un día!

Son. XXVI, 35.

pues á sido en un ora todo aquello deshecho en que toda mi vida fue gastada.

Can. III, 43-45.

Junto todo mi bien perdí en un ora,

Egl. II, 336.

En su comentario 156, Herrera se refiere al Son. XXVI y al XX e identifica sus fuentes en Petrarca y Estacio:

Com' perdi agevolmente in un mattino quel che 'n molt' anni a gran pena s'acquista!

CCLXIX, 13-14.

cuncta in cineres gravis intulit hora.

Silvas, 2 [.54].

8 Cf. H-156 y H-546 en Garcilaso de la Vega y sus comentaristas, ed. de A. GAllego Morell, Madrid, 1972, 2.2 ed., págs. 381 y 515.

- Cf. Garcilaso de la Vega, Obras completas, ed. de E. L. Rivers, Madrid, 1981, 2." ed., pág. 94. Todas las citas de Garcilaso han sido tomadas de esta edición.

- Con respecto a las enmiendas de este verso, cf. Rivers, ed. cit., págs. 134-135. 
Es fundamental para nuestros propósitos señalar inmediatamente una importante diferencia. Ambas fuentes son lamentos fúnebres. El toscano llora juntamente la pérdida de Laura y de su protector, el cardenal Giovanni Colonha $^{\circ}$, mientras que Estacio se refiere a la muerte del joven liberto Glaucia ?. Otra fuente aportada por Mele también pertenece a los poemas In morte del Canzionere:

\title{
Ai, Morte ria, come a schiantar se' presta
} il frutto de molt' anni in sí poche ore!

\section{CCCXVII, 7-8 8 .}

Garcilaso, en cambio, está hablando de los desengaños del amor. Durante un tiempo se pensó que el Son. $\mathrm{X}$ había sido escrito con motivo de la muerte de una amada, pero los análisis de Lapesa han demostrado que no hay ningún indicio seguro para tal afirmación ${ }^{0}$. Los versos del Son. XXVI y de la Egl. II entran, sin lugar a dudas, en el marco de las lamentaciones amatorias y los de la Can. III parecen entremezclar a éstas con el desengaño ante la ingratitud de los poderosos.

Es verdad que el terceto de Petrarca da la impresión de querer expresar una reflexión de carácter general. Es decir, que iría más allá del episodio personal que da origen a la composición para contemplar desde su desconsuelo qué amenazas acompañan la existencia del hombre. El terceto completo dice así:

\author{
O nostra vita ch' è sí bella in vista, \\ com perde agevolmente in un matino \\ quel che 'n molti anni a gran pena s' acquista!
}

Pero de todos modos la reflexión garcilasiana surge las cuatro veces en un contexto diferente. Caben dos posibilidades: que exista una fuente intermedia que aún no ha sido estudiada o que Garcilaso, haciendo uso como tantas veces de su autonomía en la imitatio, orientó la meditación hacia otras peripecias existenciales.

Daremos ahora un paso más, relacionado con el problema de los códigos poéticos, una de esas diferencias primordiales dentro de la totalidad de la obra a que nos referíamos al principio. F. Rico ha demostrado que los ma-

- Cf. Petrarca, F., Opere, ed. de E. Bigi, Milán, 1964, pág. 196.

7 Cf. Stace, Silves, Texte établi par H. Frère, traduit par H. IzaAc, París, "Les Belles Lettres", 1944, vol. I, pág. 55.

8 Cf. Rivers, ed. cit., pág. 135.

- Lapisa, R., La trayectoria poética de Garcilaso, Madrid, 1968, 2. ed., pág. 128.

LXVII, $10^{\circ}-2 .^{\circ}-8$ 
teriales petrarquescos pasaron a formar parte de la poesía castellana por dos caminos diversos. Uno de ellos es el muy claro y evidente de toda la escuela garcilasista. El otro, mucho más difícil de identificar, es el de la elaboración de tales materiales dentro del marco concientemente no petrarquesco del estilo de los cancioneros ${ }^{10}$. Y ocurre que Garcilaso también fue un poeta cancioneril y que conservamos algunas coplas suyas, entre las cuales mucho nos ha llamado la atención la VI. Dice el título que registra la edición de Rivers: "A una señora que, andando él y otro paseando, les echó una red empeçada y un huso començado a hilar en él, y dixo que aquello avia travajado todo el día" ${ }^{11}$. La copla en cuestión dice así:

De la red y del hilado hemos de tomar, señora, que echáys de vos en un hora todo el travajo pasado;

y si el vuestro se ha de dar a los que se pasearen, lo que por vos trabajaren ¿dónde lo pensáys echar?

El concepto es el mismo de los versos que citábamos más arriba. La belle sans merci echa a rodar en muy poco tiempo los trabajos a los que el amante ha dedicado su vida y en los que cifraba su dicha. La semejanza de la expresión se impone por sí misma:

... echáys de vos en un hora todo el travajo pasado;

¿Quién podría reconocer bajo el tono galante y el ingenio del juego conceptual del poemita, la grave meditación petrarquesca de raíz clásica? Rico nos brinda varios ejemplos similares en su estudio. Nosotros contamos en este caso con el apoyo mediador de las poesías de Garcilaso citadas, pertenecientes todas al código petrarquista, en las cuales veíamos claramente cómo adoptó este motivo tomado de la fuente italiana.

Ya hemos subrayado las diferencias en cuanto a las situaciones referidas. Vamos a estudiar ahora las particularidades semántico-estructurales de este motivo en Garcilaso.

10 Rico, F., "De Garcilaso y otros petrarquismos", Revue de Littérature Comparée, LII (1978), págs. 325-338.

11 Con respecto a los diversos títulos de esta copla, cf. Rivers, ed. cit., pág. 61. 


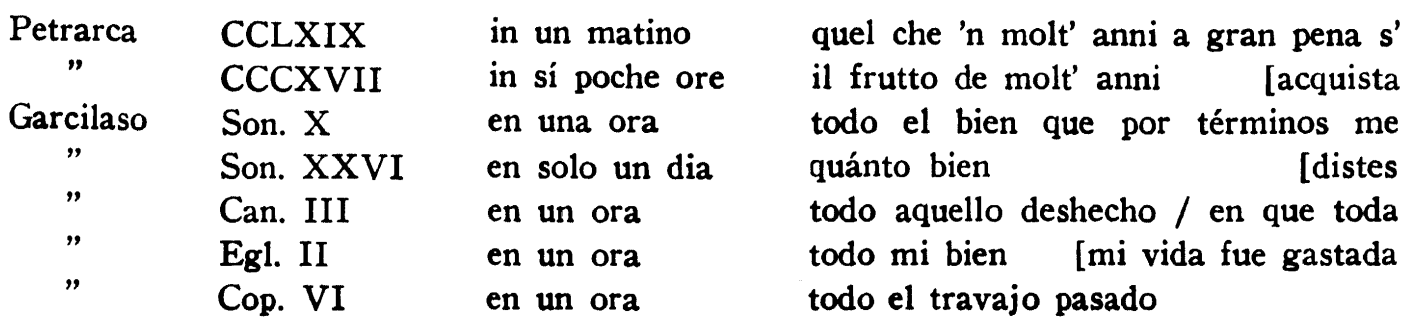

En la primera columna vemos que las expresiones petrarquescas "en una mañana" y "en $\tan$ pocas horas" se han transformado en cuatro de los cinco casos en una duración de tiempo mucho más breve formulada con un término semánticamente más abstracto: "en una hora". En cuanto a "solo un día", si bien no podemos decir en rigor que es más abstracto que "una mañana", sí podemos señalar que resulta de un carácter mucho más general e indeterminado. Un proceso de síntesis y generalización se nota también en tres casos de la segunda columna, sobre el total de cinco. Es importante detenernos aquí, por un momento, en una digresión. Con un criterio simplista se podría concluir rápidamente que la poesía de Petrarca es de un carácter mucho más sensorial, mientras que en Garcilaso priman los procesos especulativos. Algo de esto hay, sin duda, pero la cuestión exige una apreciación mucho más matizada. Es verdad que entre los sustantivos empleados con más frecuencia por Garcilaso se cuentan los que designan conceptos fundamentales para la estructura del pensamiento occidental - 'mal', 'bien', 'parte', 'todo', 'fin', etc.-. Pero por medio de recursos retóricos, métricos o sintácticos, el poeta logra establecer desde cada uno de estos sustantivos una doble apelación al receptor de lo abstracto-sensitivo y de lo intelectual-emotivo. Es éste un problema complejo que se refiere a un rasgo esencial de los usos léxicos de Garcilaso y que hemos tratado extensamente en nuestra tesis doctoral ${ }^{12}$. Aquí sólo queremos dejar planteada la cuestión.

Hemos dicho que los versos de Petrarca que se han señalado como fuentes pertenecen a poemas In morte. También Garcilaso dedica alguna de sus composiciones a la pérdida de la amada y en una de ellas percibió Herrera el rastro del motivo que estamos revisando. Curiosamente, los críticos modernos no han vuelto a subrayar esta similitud. Se trata de los versos:

En poco espacio yazen los amores, y toda la esperança de mis cosas,

Son. XXV, 5-6 18 .

12 Carrizo Rueda, S., Las transformaciones en la poesía de Garcilaso de la Vega, Madrid, Universidad Complutense, 1984, inédita.

18 Cf. H-151 en Garcilaso y sus comentaristas, ed. cit., pág. 380. 
A raíz de los cuales, Herrera recuerda " $\mathrm{O}$ quánto bien ...”. Es también el mismo Herrera quien cita otra fuente de Petrarca, el poema CCCXXXI; Tamayo añade el CCCXXVI y Mele el CCXCII.

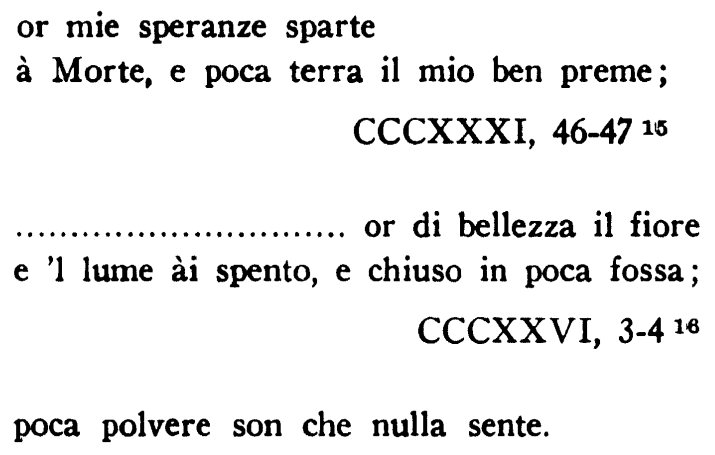

CCXCII, $8^{17}$.

Es evidente la influencia de estos versos en los de Garcilaso. Sin embargo, un análisis algo detenido de los de Petrarca nos demuestra que el motivo del cual estamos hablando, en cierto modo se les superpone al dar paso a la forma que genera el poeta español. En el poema CCXCII el italiano dedica los nueve primeros versos a los ojos, los brazos, el rostro, los pies, el cabello, la sonrisa de Laura y a los efectos que producían en él, para oponerlos al "poca polvere son che nulla sente". En el CCCXXVI la oposición es entre 'bellezza', 'fiore', 'lume' y 'poca fossa'. En cuanto al CCCXXXI, si bien es el más semejante al de Garcilaso, difiere básicamente en que se trata de una canción, lo cual da lugar a Petrarca para extenderse varios versos sobre su esperanza cuando Laura aún vivía, para terminar con la triste realidad del presente expresada en los dos versos citados.

Otras vez nos encontramos con un proceso de síntesis, abstracción y generalización, similar al que hemos visto: por una parte, resuenan en el "poco espacio" garcilasiano el "poca fossa", "poca terra", "poca polvere", pero resalta la mayor abstracción semántica de 'espacio'; por otra, han desaparecido el recuerdo de los encantos de la amada, las connotaciones de plenitud vital de 'belleza', 'flor' o 'luz' y la historia de los altibajos de la esperanza. En Garcilaso todo ello queda prietamente contenido en :

los amores,

y toda la esperança de mis cosas,

\footnotetext{
14 Cf. Rivers, ed. cit., pág. 132.

16 Cf. Bigi, ed. cit., pág. 236.

16 Cf. íd., pág. 232.

17 Cf. íd., pág. 210.
} 
De este modo, la oposición "poco espacio" / "toda la esperanza" se aproxima semántica y estructuralmente a las variantes que hemos visto de "en una hora" / "todo el bien".

En este punto recurrimos al concepto de “isotopía”, tal como lo ha definido Greimas: un haz de rasgos semánticos recurrente implicado en el discurso y que se hace evidente a través del análisis textual ${ }^{18}$. Si bien los versos de Petrarca constituyen fuentes evidentes, necesitamos de la lectura de las isotopías para comprender cómo funcionan dentro del sistema de Garcilaso. En este caso, una reflexión que surge a raíz de la muerte -com perde agevolmente in un matino ...- en el poeta español aparece aplicada a varios sucesos de la existencia humana. Además no sólo se presenta como oposición entre grandes afanes y finales más dolorosos aún por lo abruptos, sino también como festiva queja de galanteos cortesanos dentro de un código poético diferente. Y retornando a la deliberada imitatio de todo el código petrarquista, vemos que el esquema semántico-estructural, tal como fue concebido por Garcilaso, se superpone a la utilización de otras fuentes. En suma : se trata siempre de expresar de modo rotundo una paradoja existencial : la fragilidad y la fugacidad que de golpe evidencian las metas de grandes esperanzas.

Hay otro caso de asimilación. Sabemos que nuestro poeta no sólo escribió su personal Canzionere, sino que también se remontó a ciertos experimentos de los géneros latinos. A éstos pertenece el epitafio para su hermano D. Hernando de Guzmán, víctima de la peste, durante la campaña contra los franceses en Nápoles. Se trata de un soneto empleado como equivalente moderno del epigrama clásico. $\mathrm{Y}$ pese a las distancias de tema y género reaparecerá nuestro motivo bajo ciertas variantes.

No las francesas armas odiosas, en contra puestas del ayrado pecho, ni en los guardados muros con pertrecho los tiros y saetas ponçoñosas; no las escaramuças peligrosas, ni aquel fiero rüido contrahecho d'aquel que para Júppiter fue hecho por manos de Vulcano artificiosas, pudieron, aunque más yo me ofrecía a los peligros de la dura guerra. quitar una ora sola de mi hado; mas infición de ayre en solo un día

18 Greimas, A. J., Du sens, París, 1970, nota pág. 10. 
me quitó al mundo y m'ha en ti sepultado, Parthénope, tan lexos de mi tierra.

Son. XVI.

Como puede apreciarse, en este caso, el primer término de la oposición se extiende durante dos cuartetos y consiste en un recuento de los peligros de la guerra. Pero el segundo término nos pone nuevamente ante una forma sintética y reencontramos la expresión "en sólo un día”. Semánticamente, estamos ante algunos significantes mucho más concretos que los de los casos anteriores y estructuralmente ante una oposición menos equilibrada, pues se da entre dos términos de extensión desigual. Pero el segundo continúa conservando los rasgos ya identificados y vuelven a perfilarse las líneas netas de la paradoja garcilasiana. -Además, "sepultado" nos remite al caso del Son. XXV, si bien aquí se produce un deslizamiento hacia el motivo del dolor por la lejanía de la patria, tan frecuente también en el poeta-.

$\mathrm{Si}$ nos quedamos ahora con los términos básicos de la oposición, podemos llegar aún más lejos dentro de otros niveles. Como se sabe, uno de los mitos preferidos de Garcilaso es el de Faetón. Al estudiar su tratamiento en la literatura española, así lo caracteriza Gallego Morell :

La caída de Faetón es símbolo de la fugacidad de todo intento, y por esto fue representación preferida en los sarcófagos cristianos. / ... /. Faetón fue símbolo de la osadía, pero es desde un hoy lejano, encarnación de lo fugaz y transitorio. / ... /. Faetón se lanzó a una carrera larga, y apenas lució en el firmamento unos instantes. (Subrayado nuestro) ${ }^{10}$.

Más adelante, al hablar de la evolución histórica, recordará que Garcilaso fue el primero en hacer de Faetón un tema poético en las letras castellanas ${ }^{20}$.

La oposición que Gallego Morell señala en el mito como significante de la fugacidad y el modo en que está formulado nos remiten evidentemente a los términos del análisis que hemos efectuado en las páginas anteriores. Pero también nos aproximamos a esta conclusión si examinamos la funcionalidad del mito dentro de los poemas en que aparece. En la El. I dedicada al Duque de Alba por la muerte de su hermano D. Bernaldino de Toledo, Garcilaso compara al Duque con Lampecia, llorando la muerte de Faetón. La comparación entre el dolor de Lampecia y el de la persona a la que va dedicado el poema proviene de una de sus fuentes, la elegía de Jerónimo Fra-

10 Gallego Morell, A., El mito de Faetón en la literatura española, Madrid, 1961. pág. 25.

20 Id., pág. 32. 
castorio $^{21}$. Pero como se sabe, esto en Garcilaso no es de ningún modo definitorio y en esta misma elegía hay un ejemplo de cómo cambió algunos versos provenientes de otra fuente ${ }^{22}$. Pensamos que es una hipótesis probable el hecho de que Garcilaso haya encontrado en estos versos una afinidad con su tema, pues Bernaldino, joven segundón de la más alta nobleza. vio truncada pronto, como Faetón, la luminosa carrera para la cual se preparaba. En cuanto al Son. XII, expresa el amante que las malogradas aventuras de Faetón e fcaro deberían servirle de ejemplo para refrenar su deseo pasional "loco, imposible, vano, temeroso". 'Loco' e 'imposible' se presentan con un carácter semántico demasiado general como para darnos alguna pista. Pero no es el caso de 'vano'. Garcilaso emplea siete veces este adjetivo aplicándolo a entidades espirituales y lo hace con el sentido de "inestable" y/o "inconsistente" ${ }^{23}$. Desde este punto de vista, creemos que una de las posibles interpretaciones de la presencia del hijo de Apolo en el Son. XII es la de aludir a la inestabilidad y la fragilidad de las metas humanas, más que a la tópica imposibilidad del amor cortés.

Si para redondear estas indagaciones nos remontamos a los temas más frecuentes en la obra, son particularmente importantes el del desengaño amoroso y el de la muerte temprana. En una dimensión macroscópica, ambos tienden a desarrollar la paradoja que hemos estudiado: la oposición entre grandes esfuerzos y esperanzas y un final que es apenas un punto en el tiempo o en el espacio. Pero si termináramos aquí, de alguna manera estaríamos reforzando el tópico de "Garcilaso el doliente" y ocurre que el estudio detenido de una isotopía lo que suele descubrir casi siempre es la diversidad, bajo una aparente uniformidad: en este caso contamos con el claro ejemplo de la Cop. VI.

Por todo esto concluimos que la lectura de las isotopías nos conduce hacia un núcleo muy importante de la obra de un poeta, que poco a poco

21 Cf. Rivers, ed. cit., págs. 216-217 y 223.

22 Se trata de una elegía de Bernardo Tasso, de la cual tomó el episodio en que Venus recupera su vitalidad y su alegría luego de la muerte de Adonis. Garcilaso se mantiene más o menos fiel a la fuente hasta llegar a los siguientes versos: "Et per le piaggie et per li colli ombrosi / del suo bel Gnido con le nymphe a Paro / guidaua dolci balli et amorosi / senza sentir giamai piu nullo amaro." Y ésta es su versión: "desordenava con lascivo buelo / el viento sus cabellos; con su vista / s'alegrava la tierra, el mar y el cielo" - vv. 238-240- Cf. Rivers, ed. cit., págs. 217 y 235-237. Los atributos animistas del cosmos en varias composiciones de Garcilaso desempeñan una importante funcionalidad dentro de todo su sistema poético, por lo cual pensamos que su uso es conscientemente intencional. Es un aspecto que también hemos indagado en nuestra citada tesis doctoral.

28 Cf. Sarmiento, E., Concordancias de las obras poéticas en castellano de Garcilaso de la Vega, Madrid, 1970, pág. 514. 
vamos comprendiendo en distintos códigos, distintos géneros, distintos niveles. Pero al mismo tiempo, los diversos modos bajo los cuales se nos descubre, conforman una constelación que nos señala diferentes derroteros a través de su universo estilístico ${ }^{24}$.

\section{Sofía Carrizo Rueda.}

24 Por supuesto, hay que subrayar que nuestro análisis se remonta a una isotopía connotativa. Cf. al respecto López Alonso, C., y DE Vicente, E., "Isotopía y análisis textual", Teoria semiótica. Lenguajes y textos hispánicos. Actas del Congreso Internacional sobre Semióticas e Hispanismo celebrado en Madrid del 20 al 25 de junio de 1983, Garrido Gallardo, M. A., ed., C. S. I. C., Madrid, 1984, vol. I, págs. 463-471. 